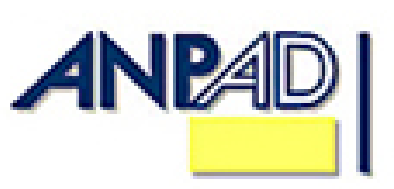

Disponível em

http://www.anpad.org.br/rac

RAC, Curitiba, v. 14, n. 5, art. 5,

pp. $854-870$, Set./Out. 2010

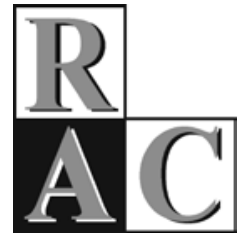

\title{
Sobre Convergência e a Prática Metodológica do Interacionismo Interpretativo na Pesquisa Acadêmica de Marketing
}

\section{Concerning Convergence and the Methodological Practice of Interpretive Interactionism in Academic Marketing Research}

João Felipe Rammelt Sauerbronn * Doutor em Administração pela EBAPE/FGV. Professor Pesquisador da FGV Direito Rio, Rio de Janeiro/RJ, Brasil.

Eduardo André Teixeira Ayrosa Doutor em Marketing pela London Business School, Reino Unido. Professor Adjunto da EBAPE/FGV, Rio de Janeiro/RJ, Brasil.

\footnotetext{
* Endereço: João Felipe Rammelt Sauerbronn

FGV Direito Rio, Praia de Botafogo, 190, sala 1325, Botafogo, Rio de Janeiro/RJ, 22250-900. E-mail: joao.sauerbronn@fgv.br
}

Copyright (C 2010 RAC. Todos os direitos, inclusive de tradução, são reservados. É permitido citar parte de artigos sem autorização prévia desde que seja identificada a fonte. 


\section{RESUMO}

Muitos fenômenos de marketing e do comportamento do consumidor não são observáveis dentro de uma perspectiva hipotético-dedutiva, e permanecem sem investigação, seja por falta de interesse da comunidade acadêmica, seja devido às carências metodológicas. Neste artigo realizamos uma discussão metodológica, na qual apresentamos nossa experiência com a utilização do Interacionismo Interpretativo em pesquisa acadêmica de marketing e suas consequências metodológicas práticas. Apresentamos as posições ontológica e epistemológica da pesquisa e mostramos como utilizamos o método do Interacionismo Interpretativo. Esta opção demonstrou ser adequada à forma de investigação, organização e operação propostas na tese. Mesmo sendo necessárias algumas adaptações, o Interacionismo Interpretativo ofereceu uma solução aplicada aos problemas de análise dos volumosos dados resultantes da abordagem qualitativa. Ao retratar essa experiência na condução de uma pesquisa de marketing de caráter interpretativo, esperamos oferecer maior compreensão a respeito desta orientação e incentivar mais pesquisadores a adotarem opções semelhantes.

Palavras-chave: métodos de pesquisa interpretativos; interacionismo interpretativo; pesquisa interpretativa de consumo.

\section{ABSTRACT}

Many issues on marketing and consumer behavior remain uninvestigated because of the research community's lack of interest or because of methodological difficulties. We present in this paper our experience using Interpretive Interactionism in academic marketing research and its consequences on methodological practice. Discussing the ontological and epistemological aspects of a doctoral dissertation, we show how we managed to use the method developed by Norman Denzin (1989). This option has proved its adequacy to the investigation approach adopted. Even though it was necessary to adapt the method, Interpretive Interactionism has offered an applied solution to the problem of dealing with the huge amount of qualitative data. Improving comprehension of interpretive research methods, we hope to offer support to other researchers interested in alternative research methods.

Key words: interpretive research methods; interpretive interactionism; interpretive consumer research. 


\section{INTRODUÇÃO}

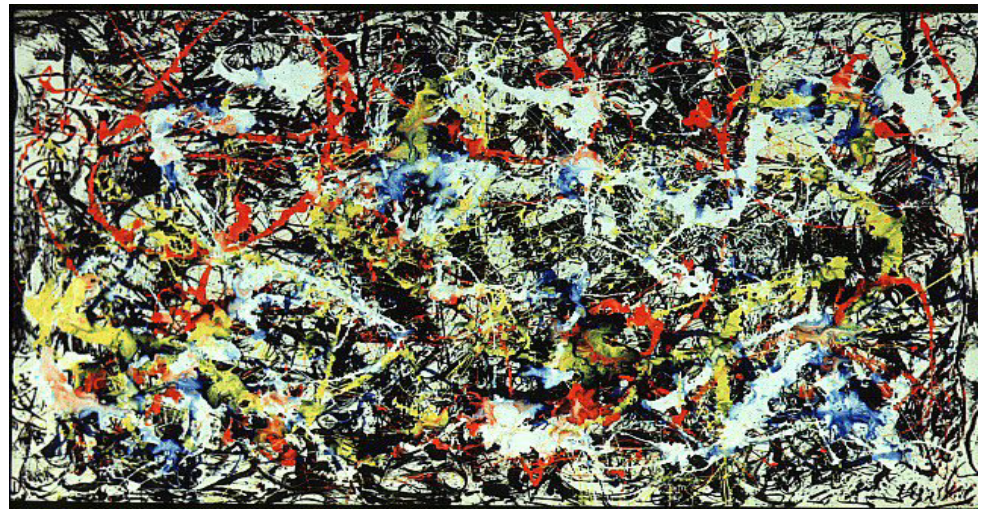

Figura 1. Jackson Pollock - "Convergence”, 1953

Fonte: Emmerling, L. (2003). Jackson Pollock: 1912 - 1956 (p. 39). Köln: Taschen. Recuperado em 14 junho, 2007, de http://www.globalgallery.com/enlarge/42776/

Em 1953, Jackson Pollock criou Convergence, quadro reproduzido na figura acima. Este quadro foi responsável pelo aumento de popularidade do pintor abstrato em razão de sua adaptação e lançamento em forma de quebra-cabeça, dez anos após a sua morte. Apesar de conter apenas trezentos e quarenta peças, este quebra-cabeça foi considerado o mais difícil de todos os tempos: não havia um assunto tradicional para ser recolocado em ordem e as pessoas não conseguiam entender a imagem contida na obra. Este quadro de Pollock refletia a imagem de sua (in)familiar arte abstrata por meio de uma cena multicolorida, sem ênfase em nenhum ponto e sem partes identificáveis em algum lugar da tela. Na verdade, há outra forma de construção na realidade do pintor, inacessível para algumas racionalidades.

A arte de Pollock inspirou nosso trabalho de pesquisa durante o doutorado. Como pesquisadores em busca de compreender as relações entre o sentimento da vergonha e o consumo, vivemos (como orientando e orientador) o desafio de trabalhar com um tema tão complexo e, ao mesmo tempo, tão estimulante. Colocamo-nos mirando com atenção para o quadro de pesquisa, em busca da descoberta das camadas de construções da realidade em meio a sua desordem. Partimos para esta pesquisa com disposição muito maior, para sermos mais observadores do que cientistas; por conta disso, acreditamos que tenhamos conseguido perceber a complexidade desta construção, embrenhando-nos por entre suas camadas de cores sobrepostas, conhecendo-a um pouco mais a cada nova observação.

Ao procurar observar experiências de consumo e as formas pelas quais o sentimento de vergonha interfere na construção de significados de consumo, encontramos na ontologia da construção social da realidade (Berger \& Luckman, 2004a, 2004b) e na epistemologia da sociologia das emoções (Denzin, 1983, 1984; Hochschild, 1979; Kemper, 1981, 2004; Shott, 1979) o suporte necessário para a exploração das relações de consumo.

Nossa posição epistemológica, em face da perspectiva de observação do sentimento da vergonha associado ao consumo, trouxe consequências diretas sobre a forma com a qual tratamos do problema. Desse modo, foi necessária a utilização de abordagem metodológica capaz de alcançar os conjuntos de significados subjetivos dos indivíduos organizados dentro de um contexto social. Essencialmente, a proposta de Denzin (1989) para o Interacionismo Interpretativo ofereceu uma solução útil e consistente para a organização da pesquisa e para a nossa operação como pesquisadores. O Interacionismo Interpretativo tornou possível o acesso às perspectivas dos consumidores por meio de suas linguagens, atitudes e pensamentos. Ao entendermos o indivíduo em ação e ao levá-lo a vasculhar seus sentimentos em situações de consumo, pudemos contar com mais recursos para a interpretação da vergonha no consumo. Como esta proposta parecia ser adequada, foi nossa opção organizar a pesquisa de acordo com as etapas propostas por Denzin (1989) para o Interacionismo Interpretativo. Mais tarde, durante a pesquisa, foi necessário que adaptássemos a forma de aplicação do Interacionismo Interpretativo, como se apresenta mais à frente. 
Este artigo apresenta o caminho metodológico traçado por nós durante a elaboração de nossa tese e, partindo desta, discute-se o uso do Interacionismo Interpretativo como método de pesquisa acadêmica em marketing. Com esse objetivo, apresentamos nossa experiência com a utilização de uma abordagem interpretativa em pesquisa acadêmica de marketing e suas consequências metodológicas práticas. Desta forma, esperamos oferecer maior compreensão a respeito de uma epistemologia alternativa para o que vem sendo produzido na área de marketing. O relato da experiência prática de utilização de um método interpretativista pode servir como incentivo para que mais pesquisadores adotem opções semelhantes e desenvolvam conhecimento original na área. Ao conhecer o caminho trilhado por nós, outros pesquisadores poderão antecipar eventuais problemas na condução de suas pesquisas interpretativas, sentindo-se mais à vontade para tomarem seus próprios caminhos.

Em alguns campos do estudo da administração, os pesquisadores parecem desfrutar de maior amplitude de opções epistemológicas e metodológicas. Esta pluralidade, contudo, não é vivenciada pelos pesquisadores de marketing (Farias, 2006; Vieira, 2000). Desta forma, parece-nos necessário iniciar este ensaio com a apresentação da proposta epistemológica da tese de doutorado desenvolvida, que serve como introdução para a perspectiva do Interacionismo Interpretativo. Em seguida, discutimos a aplicação do método proposta por Denzin (1989) e a experiência prática da utilização do método. Em seguida, são apresentadas algumas reflexões e possibilidades a respeito do uso do Interacionismo Interpretativo como possibilidade para o tratamento de outros problemas de marketing e comportamento do consumidor e são feitas considerações finais.

\section{ApresentaÇÃo da Proposta EpIstemológica da Pesquisa}

A pesquisa desenvolvida nessa pesquisa de doutorado estava alinhada com a perspectiva de inserção dos sujeitos do marketing dentro de um mundo social, o que os capacita a estarem disponíveis para influenciar e serem influenciados por este mundo. Os significados das expressões humanas não são fixos; dependem das formas de organização das relações entre a expressão e o contexto no qual ocorrem. O significado de toda expressão humana é contextual e depende de certas categorias de interação humana (Garfinkel, 1967; Scheff, 1990).

Existe a necessidade de buscar um caminho que seja capaz de capturar e analisar os valores e significados emanados do mundo social. O consumo carrega uma série de símbolos e significados que dificilmente seriam percebidos e analisados sem a utilização de um método qualitativo de pesquisa com orientação interpretativista. A realidade em que estão insertos os consumidores é socialmente construída e isto significa que o instrumento de pesquisa proposto precisa ter recursos capazes de compreender uma série de eventos e esforços oriundos das construções sociais que envolvem trocas entre consumidores e vendedores. Tais eventos não serão captados sem a participação direta do pesquisador, o que põe por terra o pressuposto positivista de afastamento. Os pressupostos positivistas não são adequados para este tipo de problema e podem ser inadequados para resolver outras questões similares.

Ao procurar observar experiências de consumo e as formas pelas quais o sentimento de vergonha interfere na construção de significados de consumo, a proposta de nossa pesquisa encontrou, na construção social da realidade (Berger \& Luckman, 2004a, 2004b) e na perspectiva da sociologia das emoções (Denzin, 1983, 1984; Hochschild, 1979; Kemper, 1981, 2004; Shott, 1979), o arcabouço necessário para a exploração das relações de consumo.

Conforme Berger e Luckman (2004a), o indivíduo apreende a realidade da vida diária como realidade ordenada, com fenômenos previamente dispostos em padrões independentes da apreensão que o indivíduo tem deles e que se impõem a sua apreensão. A realidade da vida cotidiana aparece já objetivada, independentemente da participação do indivíduo. É neste ponto que a linguagem ganha importância, pois é utilizada na vida cotidiana como fonte dos significados dos objetos e determinante da ordem em que os objetos adquirem sentido. Por conseguinte, é por mediação da linguagem que a 
vida cotidiana ganha significado para o indivíduo: a linguagem marca as coordenadas da vida do indivíduo na sociedade e preenche esta vida de objetos dotados de significação (Berger \& Luckman, 2004a).

A opção pela observação dos fenômenos emocionais de consumo, a partir de uma abordagem social, se manifestou viável, à medida que o fenômeno emocional foi entendido desta forma por alguns pesquisadores das emoções. Partindo dos conceitos de Shott (1979), Hochschild (1979) e Kemper (1981), que enfatizam o componente social das emoções, Denzin (1983) propõe uma definição que engloba diferentes áreas, priorizando a característica interacional do fenômeno: "emoção é um processo social, interacional, linguístico e fisiológico que busca seus recursos no corpo humano, na consciência humana e no mundo que rodeia a pessoa” (p. 404). Para Denzin (1983), as emoções não são apenas respostas a fatores fisiológicos, culturais e sociais; elas são processos interativos que podem ser mais bem entendidos como ações que envolvem o self e outras interações. Esta abordagem desloca o foco de análise do fenômeno emocional em direção a uma abordagem mais próxima da sociologia.

A partir de conformação de mundo mais complexa e, por consequência, de relações de consumo mais complexas, o acadêmico de marketing se encontra em posição incômoda: ao mesmo tempo que encontra soluções para alguns problemas de consumo, descobre outros tantos em que não consegue penetrar. O limitado repertório epistemológico e metodológico se reflete em sua produção e no descompasso entre o desenvolvimento da disciplina e os problemas com que se depara (Brownlie, Saren, Wensley, \& Whittington, 1999; Hudson \& Ozanne, 1988; no Brasil: Casotti, 1998). Ao incorporar novas propostas metodológicas em seu repertório, a pesquisa acadêmica de marketing pode alcançar novos horizontes, tornando-se capaz de gerar corpo teórico próprio. Na conformação de pesquisa interpretativa, baseada no indivíduo em ação, foi necessária a utilização de ferramental metodológico alinhado à proposta interpretativa. A opção ontológica e epistemológica adotada durante a pesquisa, a respeito dos sentimentos vividos durante o consumo, encontrou consistência metodológica no Interacionismo Interpretativo (Denzin, 1989). Assim, apresentamos a seguir a proposta metodológica que foi utilizada na pesquisa e a experiência de sua operação.

\section{INTERACIONISMO INTERPRETATIVO}

O Interacionismo Interpretativo é proposta metodológica voltada para os problemas vividos pelos indivíduos no mundo das experiências e seus contextos sociais. A sua denominação exibe seus antecedentes: o argumento do Interacionismo Interpretativo parte do Interacionismo Simbólico de Blumer e procura conciliar esta proposta com a perspectiva interpretativa da fenomenologia associada à hermenêutica, criando, assim, estudos que têm sentido para o mundo pós-moderno da experiência humana (Denzin, 1989). Seu desenvolvimento parte do pressuposto de que as ações humanas se dão em direção ao outro, com o outro e a partir do outro, em processos mútuos que resultam nas experiências interacionais mediadas por símbolos e pela linguagem. A partir das interações dos indivíduos passam a surgir relações entre os objetos e seus significados; estes significados sobrepostos passam a compor um repertório de sentido para os objetos, de acordo com os contextos das interações.

O método proposto por Denzin está baseado nas compreensões das pessoas sobre suas vidas. Os significados que as pessoas acessam para seus domínios são baseados nas suas interpretações, nas suas interações sociais e nas formas com que estas pessoas constroem uma ordem social negociada e acordada. Para Denzin (1989), os indivíduos não só respondem ou se vão adequando ao mundo social, mas também podem contribuir para a sua construção. 


\section{A Perspectiva do Interacionismo Simbólico}

Para que possamos apresentar a proposta de Denzin acerca do Interacionismo Interpretativo e cumprir a proposta deste trabalho é necessário que sejam expostos e analisados seus antecedentes. Como se pode perceber, até mesmo pela forma com a qual Denzin deu nome à sua proposta, as interações dos indivíduos são a base de sua proposta metodológica e o Interacionismo Simbólico serve como principal elemento constitutivo do Interacionismo Interpretativo.

O princípio básico do Interacionismo Simbólico propõe que qualquer esquema social humano, orientado empiricamente, deva respeitar o fato de que, em primeira e última instância, a sociedade humana é constituída de pessoas engajadas em ações. O Interacionismo Simbólico dá conta da natureza da sociedade humana e da vida humana em grupo e, dentro desta perspectiva, os grupos humanos são formados por seres humanos comprometidos com ações. Estas ações consistem em múltiplas atividades que os indivíduos realizam em suas vidas, enquanto se encontram uns com os outros e lidam com a sucessão de situações com que são confrontados. Assim, os grupos humanos ou sociedades existem em ação e devem ser observados em termos de suas ações. A vida em grupo pressupõe necessariamente as interações dos membros do grupo ou, posto de outra forma, uma sociedade consiste em indivíduos interagindo.

Para Blumer, as interações sociais desempenhadas pelos indivíduos detêm importância fundamental para a compreensão dos fenômenos sociais e deveriam ser contempladas pelas ciências sociais. Assim, Blumer considerou três premissas básicas para sua proposta: 1) os seres humanos agem sobre os objetos com base nos significados que aqueles objetos têm para eles; 2) os significados dos objetos originam-se na interação social que o indivíduo tem com outro; e 3) os indivíduos lidam com os significados e os modificam por meio de um processo interpretativo utilizado pela pessoa, ao lidar com as coisas que encontra.

Parece claro como o processo de significação e ressignificação ocorre no mundo do consumo. Afinal, um produto, como a roupa, pode assumir diversos significados para os consumidores, desde a simples proteção do corpo até a explicitação de uma opção de vida. Decerto, o universo de consumo é universo eminentemente simbólico que guarda importância fundamental para os significados de vida dos indivíduos (Baudrillard, 1991; Belk, 1985).

Dentro da perspectiva interacionista, os significados emergem do processo de interação das pessoas. Consequentemente, o significado de um objeto se constrói a partir das ações de outros indivíduos sobre um indivíduo que considera o objeto: as ações dos demais definem a coisa para o indivíduo (Blumer, 1998). Blumer propõe que os significados dos objetos são produtos sociais, formados a partir das atividades executadas pelas pessoas em suas interações com outros indivíduos.

Enquanto o significado das coisas é formado no contexto das interações sociais e deriva da pessoa envolvida nesta interação, o uso do significado pela pessoa envolve processo interpretativo dividido em duas etapas: 1) a indicação do indivíduo a si mesmo relativamente às coisas sobre as quais ele age, processo social internalizado, em que o ator interage consigo mesmo; e 2) a interpretação, etapa na qual o ator seleciona, verifica, reagrupa e transforma os seus significados, à luz da situação em que está inserto e da direção de sua ação (Blumer, 1998).

\section{Os Constituintes Fenomenológicos do Interacionismo Interpretativo}

O Interacionismo Interpretativo adota a posição de Heidegger e não parte de considerações sobre um eu abstraído do mundo externo e da comunidade humana, mas a partir da experiência cotidiana: a vida cotidiana é a vida do indivíduo. A fenomenologia de Heidegger suspende, assim, o exame dos determinantes subjacentes às crenças das pessoas, para procurar descrever as implicações, as intenções e os efeitos daquilo que os indivíduos dizem, fazem e que acreditam que seja verdadeiro (Goulding, 1999). 
Como forma de instrumentalização do método fenomenológico, Heidegger propôs a abordagem interpretativa, ou hermenêutica, e o círculo hermenêutico para (re)criação do conhecimento: (1) compreensão; (2) interpretação/ação; e (3) nova compreensão. A interação dos sujeitos, então, é compreendida a partir da linguagem e a redução do sentido cotidiano das palavras faz com que os significados implícitos sejam revelados. Os elementos essenciais da linguagem são a expressão e a significação; mas a expressão, por si só, pode ser insuficiente como qualificação: o significado é associado aos fonemas da palavra (Andrade \& Tanaka, 2001). Conseguintemente, é por mediação da linguagem que a vida cotidiana ganha significado para o indivíduo: a linguagem marca as coordenadas da vida do indivíduo na sociedade e enche esta vida de objetos dotados de significação (Berger \& Luckman, 2004a).

A proposta metodológica do Interacionismo Interpretativo fica mais clara, quando se trata de sua operação. A seção seguinte trata da proposta de Denzin para a operacionalização do Interacionismo Interpretativo: descreve suas etapas e procura situar o leitor no caminho que adotamos, em seguida à apresentação deste método.

\section{O MÉTODO DO INTERACIONISMO INTERPRETATIVO}

A operacionalização metodológica do Interacionismo Interpretativo compreende seis etapas, que são interdependentes. Durante a formulação do problema de pesquisa o pesquisador tem de considerar as características do problema (da forma em que lhe é revelado) e suas convicções científicas. O Interacionismo Interpretativo tem proposta direta de atuação: examinar como (e não por que) experiências problemáticas são organizadas, percebidas e construídas pelos indivíduos em interação e como são construídos os significados associados a estas experiências. O pesquisador procura descobrir como a ação problemática (ou evento) em questão age sobre a organização e a construção de significados para as pessoas estudadas (Denzin, 1989).

Em seguida, o pesquisador deve analisar criticamente a forma com a qual este problema tem sido apresentado, estudado e analisado em outras pesquisas existentes e como as teorias relativas a este problema foram construídas. Esta desconstrução serve para que o pesquisador desvende os vieses e os pré-conceitos envolvidos e consiga localizar o seu estudo em contraste com o corpo de trabalho existente. Esta etapa tem função equivalente à revisão de literatura, mas inclui uma visão crítica que desafia a racionalidade e objetividade dos estudos realizados previamente. Descontruir significa percorrer o texto além de sua sonoridade metodológica. Significa mostrar que sua história pode ter sido ocultada ou excluída, apontar quais vozes foram impedidas de se manifestar, mostrar as oposições hierárquicas nas quais o texto está construído e examinar tanto o que foi falado, quanto o que foi deixado de lado (Mohr, 1997).

A captura, passo seguinte, envolve a coleta de casos múltiplos e histórias pessoais que incorporem o fenômeno em questão e a localização das crises e epifanias na vida das pessoas estudadas. Assim, devem ser obtidas dos sujeitos em questão múltiplas histórias pessoais e auto-histórias que envolvam o tópico investigado. Alguns momentos experienciados pelos indivíduos são únicos, marcam suas histórias de vida e atuam na configuração de seus arranjos de compreensão do mundo, suas racionalidades e emoções. Estes momentos colocam o indivíduo em face do seu mundo, reconstruindo-o e dando-lhe novos formatos, a partir das novas interações presenciadas e suas relações com os resultados das interações anteriores. Tais momentos são as epifanias.

O termo epifania denomina as festas cristãs do Dia de Reis, quando a santidade de Deus é celebrada e a vida é abençoada. Denzin (1989) pega emprestado de James Joyce o significado que este último construiu para as epifanias, ao descrever momentos de interação que deixam marcas (positivas ou negativas) na vida das pessoas. Frequentemente, estes momentos marcantes são experienciados como problemas pessoais que se tornam assuntos públicos, posteriormente. Com a constituição de uma sociedade baseada no consumo, como propõem Douglas e Isherwood (2004) e Baudrillard (1991), as 
experiências individuais ou coletivas que ocorrem em situações de consumo passaram a ter importância central na vida dos indivíduos.

Durante a captura, o pesquisador tem de ser capaz de construir uma descrição densa das experiências coletadas junto aos indivíduos. Conforme proposto por Denzin (1989), a partir do conceito de Geertz (1989), a descrição densa procura resgatar os significados e experiências que ocorreram em situações no campo e capturar as interpretações que as pessoas dão aos eventos que foram registrados. O objetivo é reportar as interpretações da forma com que elas foram apresentadas durante a interação e, assim, estabelecer as bases para uma interpretação densa. Muito mais do que descrever uma situação acessada, com os elementos participantes e os interesses envolvidos nos fenômenos, a descrição densa procura deixar explícitas todas as estruturas superpostas, referências e implicações, por intermediação das quais o pesquisador pode compreender o fenômeno de forma mais completa.

A descrição densa procura descobrir os meios que formam e estruturam as experiências dos sujeitos e leva o leitor ao coração da experiência que está sendo interpretada. Assim, o pesquisador deve assumir que todo o significado é simbólico e operar tanto na superfície quanto nas profundezas, em nível micro e macro: a tarefa é produzir descrições detalhadas que dêem conta das experiências vivenciadas pelos indivíduos.

Ao construir descrições detalhadas das experiências de consumo vividas, tem início o bracketing ${ }^{(1)}$. Nesta fase, o fenômeno é tratado como texto (ou como documento) e é confrontado com seus próprios termos, distante dos termos em que é interpretado na literatura existente. O fenômeno é retirado do mundo no qual está inserto e dissecado, de forma que seus elementos e estruturas essenciais sejam revelados, definidos e analisados.

O bracketing permite que o pesquisador liste os elementos constituintes de um fenômeno e proponha uma (re)construção do fenômeno - a fase seguinte. O pesquisador classifica, ordena e rearranja o fenômeno de forma coerente. Durante a construção, os elementos enquadrados do fenômeno são listados e ordenados da maneira em que ocorrem dentro do processo experiencial. O pesquisador indica como cada elemento afeta os demais e se relaciona com os outros elementos no processo estudado e propõe uma forma de construção do fenômeno em sua totalidade. O objetivo desta etapa é recriar a experiência vivida em termos de seus elementos constituintes analíticos.

A pesquisa interpretativa de Denzin (1989) utiliza o círculo hermenêutico, ao colocar o pesquisador e o sujeito da pesquisa no centro do processo. Um círculo interpretativo (ou duplo-hermenêutico) é implicado, já que o sujeito que apresenta uma história pessoal está no centro da vida que é contada; o pesquisador, que lê e interpreta esta história, está no centro de sua interpretação. Duas estruturas interpretativas, deste modo, interagem. Cada depoimento de um sujeito pesquisado representa um círculo que se descortina sobreposto ao nível que o pesquisador é capaz de vivenciar. O pesquisador vivencia a seu modo a experiência e as histórias particulares do sujeito. Estes círculos nunca estarão completamente superpostos, uma vez que as experiências do sujeito nunca serão as mesmas que a, do pesquisador: a expectativa se dá em torno da compreensão.

Ao interpretar as estruturas do fenômeno, o pesquisador lhe dá significado dentro do mundo social. A contextualização traz o fenômeno para os ambientes social e pessoal dos indivíduos estudados. A contextualização objetiva mostrar como o mundo da experiência vivida altera e forma o fenômeno estudado, uma vez que as estruturas das experiências serão alteradas e formatadas na medida em que forem vividas, descritas e a elas se atribuam significados por parte de seus participantes. 


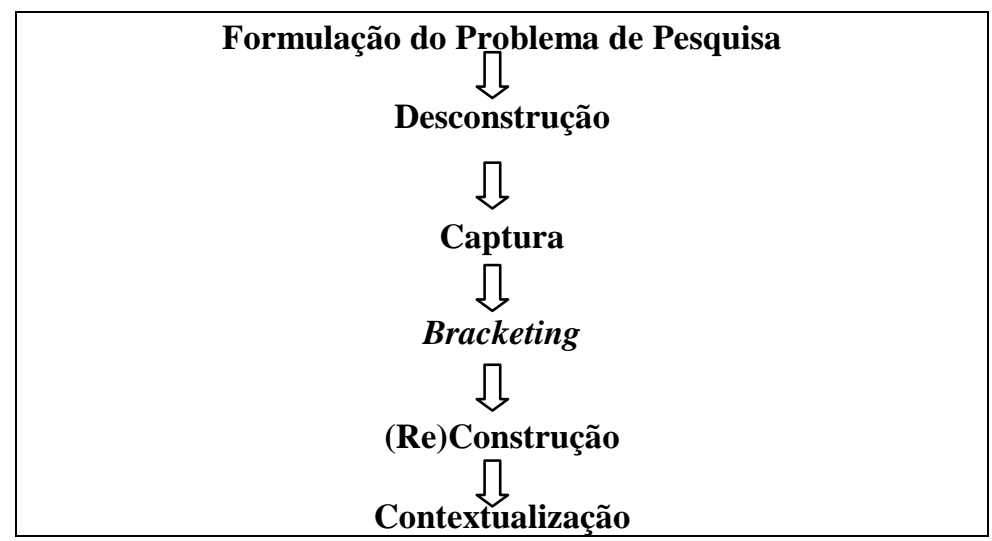

Figura 2. Etapas do Processo Interpretativo

Fonte: Adaptado de Denzin, N. K. (1989). Interpretive interactionism (p. 48). London: Sage.

\section{PRÁTICA DO INTERACIONISMO INTERPRETATIVO}

A proposta metodológica desenvolvida em nossa pesquisa seguiu os procedimentos propostos por Denzin (1989) e a experiência vivida em cada etapa de aplicação do Interacionismo Interpretativo é tratada nesta seção.

\section{Formulação do Problema de Pesquisa e Determinação do Espaço do Pesquisador}

Na verdade, a definição do problema de pesquisa dentro de uma proposta interpretativa não difere da formulação do problema de pesquisa de qualquer outra pesquisa. Entretanto, a posição do pesquisador e o espaço determinado para ele dentro do processo têm de ser pensados de maneira diferente de uma pesquisa positivista tradicional.

A pesquisa de caráter interpretativo oferece ao pesquisador uma posição bastante próxima do objeto a ser pesquisado e pressupõe sua capacidade de interagir com o mundo a sua volta e interpretá-lo para que o problema possa ser condizentemente formulado. As convicções do pesquisador não são deixadas de lado e a pesquisa interpretativa exige que o pesquisador seja capaz de se relacionar com o mundo de forma particularmente crítica. O problema de pesquisa da tese propunha investigar como o sentimento da vergonha se relaciona com a formação e reconfiguração de significados de consumo. Como o pesquisador também é consumidor e também tem sentimentos, a proposta do Interacionismo Interpretativo não exige o abandono desta condição, mas requereu uma capacidade de análise mais profunda entre ele e os sujeitos da pesquisa.

\section{Desconstrução}

Como o tema da tese não era plenamente desenvolvido dentro da área do marketing e não estava encerrado em uma única disciplina especificamente, dedicamos esta etapa a percorrer várias disciplinas. A releitura destas disciplinas buscou oferecer uma análise cuidadosa a respeito de consumo, significados e vergonha. Nossa proposta de desconstrução levou em consideração que a interferência do sentimento da vergonha sobre os significados de consumo não apresenta estudos específicos anteriores. Desta forma, nossa opção foi dividir esta etapa em duas: a desconstrução do sentimento da vergonha e a desconstrução dos significados de consumo. Desse modo, buscávamos alcançar a essência da relação entre vergonha e consumo. 
A primeira seção apresentava múltiplas perspectivas a respeito do sentimento da vergonha. Ao contrário do consumo, que é problema diretamente ligado à disciplina do marketing, a vergonha não é tema do marketing ou mesmo de uma única disciplina especificamente, pelo que estudar a vergonha exigiu percorrer um caminho que passava por outras disciplinas. A segunda seção tratava de significados de consumo e era ligada de forma direta, porque considerava que o sentimento da vergonha tem capacidade de interferir na maneira com a qual os indivíduos constroem seus significados de consumo. A discussão dos significados de consumo e a conceptualização do sentimento da vergonha ofereceram os subsídios necessários para o desenvolvimento de uma proposta teórica para a compreensão da relação entre a vergonha e os significados de consumo.

\section{Captura, Bracketing e (Re)Construção}

Durante a operação do método do Interacionismo Interpretativo, algumas das etapas propostas por Denzin (1989) transcorreram de maneira simultânea. Depois de passarmos por duas etapas bem distintas e separarmos a formulação do problema de pesquisa e a desconstrução em capítulos distintos, não foi possível separar as etapas de coleta, bracketing e (re)construção durante a operacionalização do método. Estas fases não apresentavam propriamente limites entre si. Conforme apontou Mohr (1997), as duas primeiras fases da operacionalização do Interacionismo Interpretativo ocorrem de forma sequencial, enquanto as demais ocorrem de forma tanto sequencial quanto interativa.

Após alguma reflexão sobre a prática do método do Interacionismo Interpretativo que conduzíamos, redesenhamos as etapas da pesquisa como forma de organizar um pouco melhor a compreensão. A rigor, a etapa de contextualização também se confundiu com a captura, o bracketing e a (re)construção. Entretanto, tomamos o cuidado de retirá-la deste mélange com o intuito de propor, de forma mais clara e consistente, a discussão de nossas interpretações a respeito da interferência do sentimento da vergonha nos significados de consumo. A Figura 3 apresenta as etapas de pesquisa consolidadas:

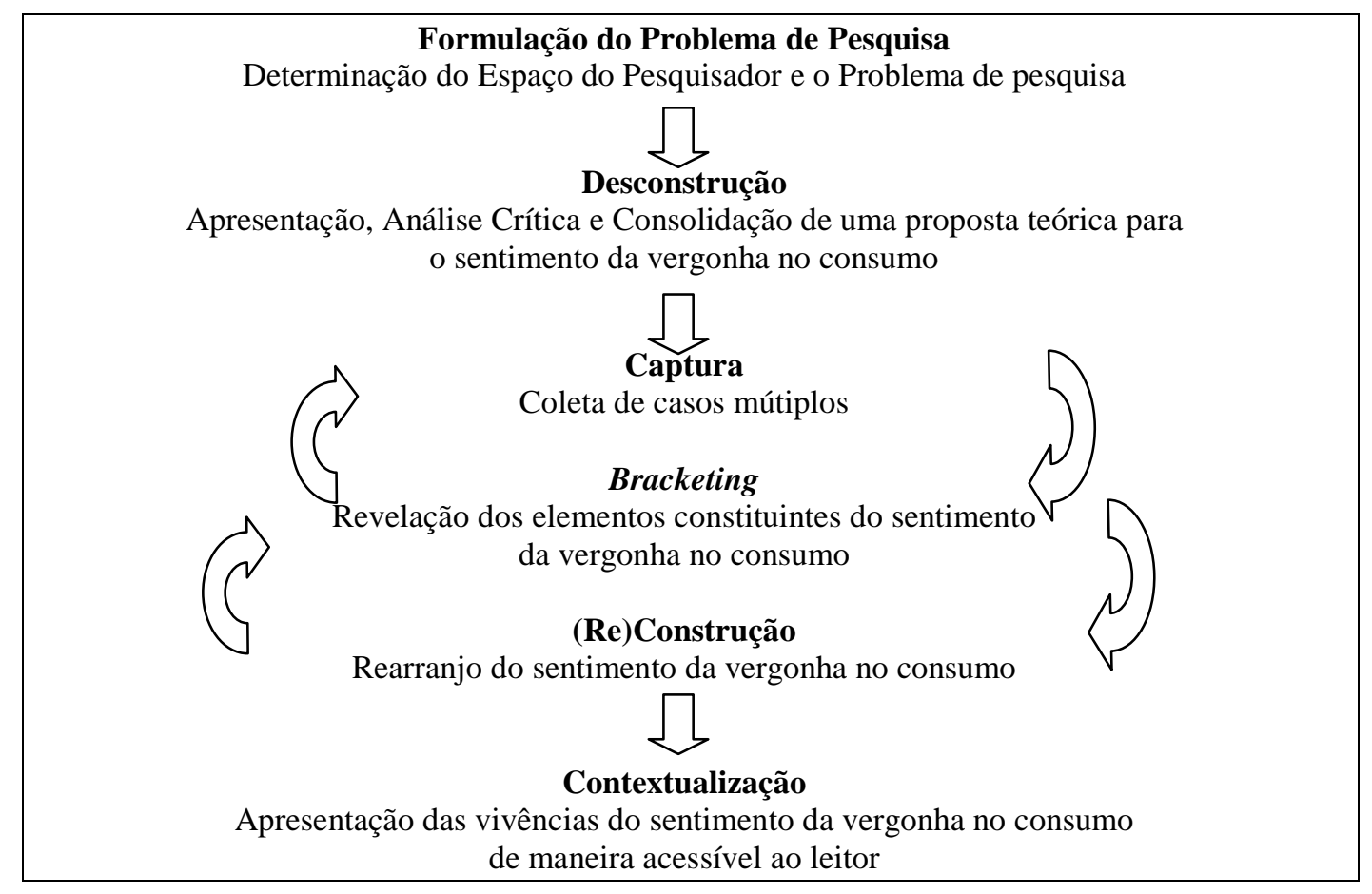

Figura 3. Etapas de Pesquisa Consolidadas

Fonte: Adaptado de Denzin, N. K. (1989). Interpretive interactionism (p. 48). London: Sage. 


\section{Operacionalização da Captura, Bracketing e (Re)Construção}

A experiência mais importante dos indivíduos ocorre na situação de estar face a face com o outro, que é o caso prototípico da interação social (Berger \& Luckman, 2004a). A escassez de tempo e a preocupação com a privacidade, contudo, se colocam como importantes impedimentos para a realização de estudos qualitativos na vida atual. E são estes dois impedimentos que precisamente tornam a entrevista em profundidade tão valiosa como meio de investigação. Essa estratégia de pesquisa nos dá acesso aos indivíduos, sem violar sua privacidade ou testar sua paciência e permitiu a captura da informação necessária para profunda análise qualitativa, sem a necessidade de que lançássemos mão de métodos mais complexos e demorados, como a observação participante ou a etnografia. O método de entrevistas em profundidade nos permitiu alcançar objetivos qualitativos cruciais, dentro de um contexto metodológico gerenciável (McCracken, 1988).

O processo de coleta de entrevistas foi dividido em duas fases: a primeira fase de entrevistas pessoais em profundidade serviu para que o tema da interação das emoções com o consumo ficasse mais nítido para nós, permitindo a melhor percepção dos enredos emocionais de consumo. Consideramos finda essa primeira etapa, no momento em que nos sentimos mais aptos a nos dedicar mais especificamente ao sentimento da vergonha. Após a décima primeira entrevista, passaram a ficar latentes, nos discursos coletados, fatores que tornaram suficientemente claro para nós que poderíamos (e deveríamos) ser mais específicos em nossas entrevistas daquele momento em diante.

Ficou evidente que não era possível definirmos um limite objetivo, em que se encerrava a exploração e se iniciava o processo de compreensão dos significados, porquanto, além de não nos dedicarmos a uma distinção cronológica dos discursos, estávamos conscientes de que não tínhamos controle da inibição ou sobre a liberdade de expressão dos respondentes. Ficou caracterizada a interatividade entre as duas fases de coleta de dados e nossa despreocupação com a eventualidade de se retornar ao discurso de respondentes, em fases distintas de análise. Mesmo tendo sido realizadas em momentos distintos da maturidade do nosso conhecimento do tema, as duas fases de entrevistas foram revisitadas exaustivamente durante o processo de bracketing.

Como maneira de efetuar o bracketing, após cada sessão de entrevista, os diálogos eram transcritos e realizávamos nova leitura e nova audição daquela entrevista. Desta forma, as frases e declarações recorrentes, relacionadas ao sentimento de vergonha no consumo, foram identificadas. Durante o bracketing permanecemos conscientes da exigência proposta por Denzin de colocar de lado qualquer consideração anterior a respeito do problema pesquisado. Por diversas vezes, retornamos às entrevistas que já haviam sido lidas e ouvidas mais de uma vez. Durante todo o período de captura e bracketing, mantivemos um arquivo com anotações, propostas de interpretação e observações a respeito dos discursos coletados.

O esforço dedicado à captura de casos interessantes para o entendimento das relações entre vergonha e consumo foi recompensado com a coleta de discursos assaz complexos já nesta primeira fase. A partir do ponto em que nos sentimos mais à vontade para direcionar o entrevistado a oferecer uma situação de consumo marcante, decidimos iniciar a segunda etapa do processo de captura e bracketing.

Na segunda etapa qualitativa, já tendo discutido grande número de experiências emocionais associadas ao consumo, realizamos nova rodada de entrevistas pessoais em profundidade, com o objetivo de irmos mais a fundo na observação de como as experiências de consumo e de vergonha no consumo são expressas pelos entrevistados em seus discursos. Já estavam mais claras em nossas mentes a forma de interação dos sujeitos dentro do processo de consumo. Assim, pudemos sofisticar bastante as nossas intervenções e procurar maior aprofundamento na compreensão das formas de atuação do sentimento da vergonha no consumo. As entrevistas tiveram um foco mais dedicado ao sentimento da vergonha e tratavam mais diretamente da exploração deste sentimento nas experiências de consumo dos informantes. O objetivo foi capturar os momentos significantes do sentimento da vergonha no consumo (as epifanias). Ainda assim, tivemos o cuidado de evitar a armadilha de envergonhar o entrevistado; não criamos situações de espirais de vergonha, conforme orienta Owens (2006). 
Nesta segunda etapa de entrevistas, pudemos buscar, de maneira mais concreta, as situações de consumo que foram importantes para os consumidores e poderiam ser consideradas epifanias. Dois encontros não foram profícuos neste sentido; mas, durante cinco entrevistas, as epifanias relacionadas à vergonha no consumo foram obtidas sem maiores problemas. Além disso, revisando as entrevistas anteriores, pudemos retornar às situações de consumo que muito envergonham nas vidas dos entrevistados durante a primeira etapa da coleta. Ao longo da pesquisa foram entrevistados quinze indivíduos do sexo masculino, nove na primeira etapa e seis na segunda.

O processo de bracketing ocorria sempre que relíamos cada um dos discursos coletados. Entrevistas da primeira fase foram constantemente revisitadas e auxiliaram a compreensão dos discursos que eram coletados. Na verdade, o processo de bracketing uniu as duas etapas de captura, mesmo tendo estas duas etapas características diferentes. Ao iniciar a construção das descrições detalhadas das experiências vivenciadas pelos indivíduos, foi muito difícil destacarmos dessa descrição o rearranjo das experiências de consumo dos entrevistados. O processo que envolve captura, bracketing e (re)construção passou a ser único e passou a não ter mais sentido separá-los. Compreendendo a reflexividade desse processo, assumimos sem detença uma posição de observação do nosso próprio processo e tentamos desenhar uma explicação para esta fusão de etapas do processo do Interacionismo Interpretativo. Considerando os discursos coletados como produtos dos entrevistados e, ao mesmo tempo, como recursos e fontes de significados utilizados por estes, o método de análise de dados aproximou-se dos procedimentos analíticos propostos por Holstein e Gubrium (2005), por meio do Analytic Bracketing.

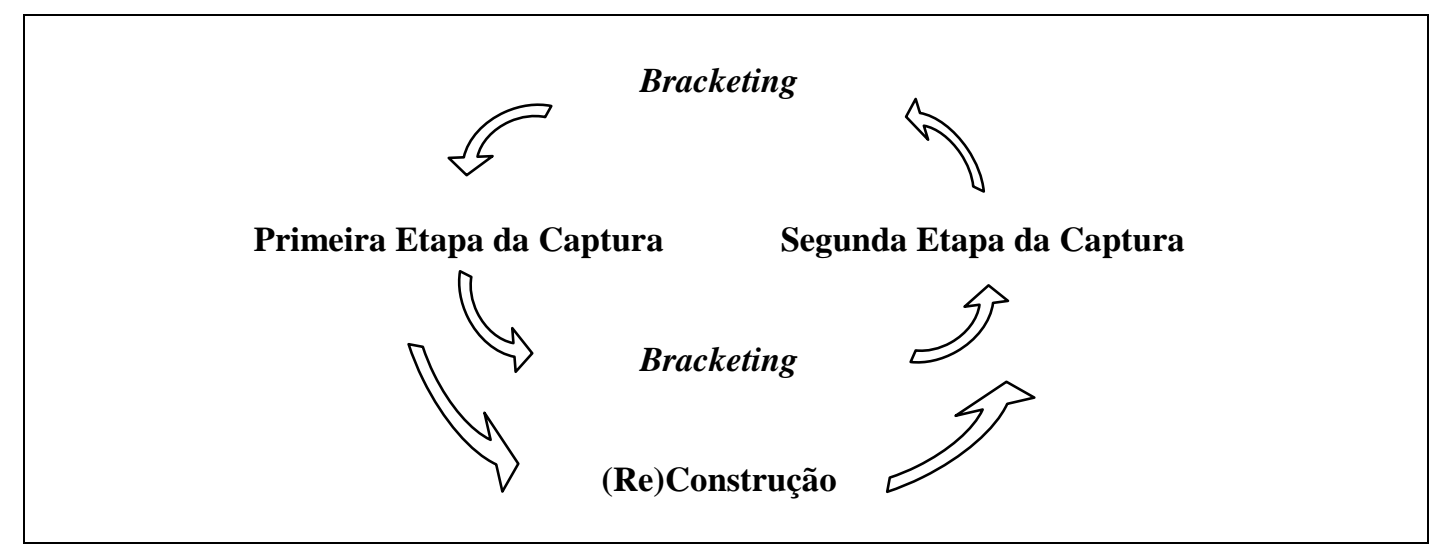

Figura 4. Processo Integrado de Captura (Duas Etapas), Bracketing e (Re)Construção

Fonte: Elaborado pelo autor

A Figura 4 mostra a integração dos processos de captura (em duas etapas), o bracketing contínuo e a (re)construção. Enquanto revisitávamos os discursos coletados anteriormente, sofisticávamos o processo de coleta da entrevista posterior. Assim, em cada entrevista realizada, nos sentíamos mais capazes de penetrar no universo do indivíduo e vasculharmos suas construções sociais que envolvessem consumo e sentimentos de vergonha. Como maneira de consolidar esta (re)construção, retomávamos, a todo o momento, nosso arquivo de anotações de campo. Os massivos dados e suas interpretações possibilitaram a (re)construção das formas de relação entre o sentimento de vergonha e os significados de consumo através dos três casos que funcionaram simultaneamente como descrições densas e (re)construções. Estes três casos reuniram os discursos de todos os entrevistados, de forma sintética, e ofereceram uma apresentação das histórias pessoais que tratam do sentimento da vergonha no consumo: Antonio, Bom Consumidor; José, Homem Funcional; e Rogério, Deslocamento Social. Mesmo tendo construído os casos a partir de diversos relatos de informantes diferentes, as citações que utilizamos eram reais e reproduziam as falas dos entrevistados. Estratégias semelhantes de reconstrução de casos, a partir de relatos de múltiplos respondentes e utilização de extratos de entrevistas, já foram sugeridas por Costa e Belk (1990).

Cada caso foi construído a partir de aspectos levantados em nossas diversas leituras e releituras das entrevistas, com os resultados de nossas interpretações deste fenômeno. A perspectiva adotada neste 
trabalho levou em consideração a biografia dos respondentes, suas histórias pessoais e a comparação dos seus discursos. Os casos serviram para que o leitor acessasse os dados coletados e pudesse ter melhor compreensão do processo de interpretação, levado a cabo na pesquisa, além de consolidar as bases para a etapa de contextualização do fenômeno da vergonha no consumo nas próprias bases dos entrevistados.

\section{Contextualização}

A última etapa do método proposto por Denzin (1989) é a contextualização. Nesta etapa realizamos a interpretação das estruturas da vergonha associadas ao consumo, da maneira como estas foram observadas nos discursos dos entrevistados. Como coloca Scheff (1990), a linguagem natural, como a que ocorre dentro de conversação espontânea, é sempre ambígua, porque muitas palavras e gestos têm mais de um significado convencional e porque, em vários graus, significados são improvisados durante o momento do encontro. Como salientam Berger e Luckmann (2004a), há contínua correspondência entre os significados individuais e os significados dos demais indivíduos que compartilham o mesmo mundo social.

Os casos de consumidores, apresentados na etapa anterior, serviram como referência e, desta forma, pudemos trazer ao leitor uma interpretação das experiências vividas pelos indivíduos entrevistados. Como forma de apresentar, de maneira mais direta, as relações entre o sentimento de vergonha e os significados de consumo observados nesta pesquisa, foram discutidas quatro situações de consumo envergonhantes que serviram para que a pergunta de pesquisa fosse respondida.

\section{REFLEXÕES E POSSIBILIDADES ACERCA DO USO DO INTERACIONISMO INTERPRETATIVO EM OUtros Problemas de MARKETING}

Dado o escopo da pesquisa realizada por nós, um desdobramento direto da utilização do Interacionismo Interpretativo está voltado para a ampliação do estudo dos fenômenos emocionais associados ao consumo. Autores advindos de tradições diferentes, como Holbrook e Hirschman (1982) e Richins (1997), já apontaram o papel ativo das emoções durante as experiências de consumo. Ainda assim, a área carece do desenvolvimento de uma pesquisa mais dedicada ao estudo dos determinantes das emoções e seus efeitos sobre os consumidores, como aponta Ahuvia (2005). Mesmo que alguns estudos mais recentes se tenham dedicado a explorar mais profundamente o papel das emoções no comportamento do consumidor, ainda há a necessidade de maior dedicação da área a este tema.

A psicologia cognitiva e seu ferramental metodológico, que dominam as atenções dos pesquisadores do comportamento do consumidor nos últimos tempos, têm-se dedicado mais ao estudo dos afetos (manifestações externas que surgem como consequência dos sentimentos), sem investigar mais profundamente os sentimentos que antecedem estes afetos e suas relações com o consumo. Seguindo a indicação de Bagozzi, Gürhan-Canli e Priester (2002), abordagens focadas nas bases sociais das emoções podem contribuir para a proposição de novas perspectivas de entendimento das relações entre emoções e consumo. Conforme apresentamos ao longo deste artigo, parece assaz confortável a indicação de que acadêmicos interessados em pesquisar as emoções associadas ao consumo possam utilizar o Interacionismo Interpretativo de forma muito produtiva. Este texto pode servir como guia e incentivo para que construam suas interpretações acerca de fenômenos emocionais relacionados ao consumo.

Além da ampliação do conhecimento a respeito de fenômenos emocionais associados ao consumo, pesquisadores ligados a outros temas de marketing também podem fazer uso do Interacionismo Interpretativo. Ao permitir o tratamento de problemas sociais e focados nos indivíduos simultaneamente, este método pode oferecer caminho metodológico sólido para o tratamento de problemas de marketing e consumo, normalmente desconsiderados por perspectivas mais tradicionais 
na área. O Interacionismo Interpretativo pode ser utilizado como suporte para propostas de estudos interdisciplinares de mercado, tratando de questões relativas ao indivíduo, ao grupo e ao consumo que podem servir a diferentes interesses que não apenas aos das empresas, mas também do Estado e da sociedade, aproximando a pesquisa de marketing das áreas de estudo das políticas públicas e Business and Society.

Assim, temas como o consumo de drogas ou comportamentos de consumo instáveis e problemáticos (excesso de endividamento, automedicação e comportamentos desviantes, por exemplo), que já fazem parte do conjunto de interesses e preocupações de novas áreas da pesquisa de consumo, como os Estudos Transformativos de Consumo (Transformative Consumer Research), ou a Teoria de Cultura do Consumidor (Consumer Culture Theory), também podem ser explorados a partir do uso do Interacionismo Interpretativo.

Mirando em direção mais próxima ao mainstream da área, manifestações do self em bens e experiências de consumo também poderiam ser mais profundamente compreendidas, se deslocássemos nossa visada. Pesquisadores poderiam utilizar o Interacionismo Interpretativo como forma de adotar uma posição mais próxima da observação das interações humanas que envolvem o processo de construção do self e suas extensões demonstradas pelas posses.

Tendo em vista a importância do aspecto humano que envolve os serviços, a possibilidade de entender o indivíduo em ação e próximo de suas interações também pode oferecer novas opções para os pesquisadores de marketing de serviços. O Interacionismo Interpretativo pode ser utilizado para tratar de aspectos relacionados aos prestadores de serviços e suas questões (emocionais ou não) relacionadas à oferta de serviço e interação com consumidores. A compreensão dos indivíduos a respeito de suas vidas poderia ser expandida para uma observação realmente interacional de como prestadores e consumidores de serviços constroem a experiência de serviços.

Gostaríamos de propor também o simples exercício metodológico que expande a percepção acerca dos problemas de consumo que estão em volta do pesquisador. Ao nos prepararmos para o mundo acadêmico, somos treinados e temos nossa proficiência testada, em face do uso de ferramentas metodológicas positivistas: testes de hipóteses, regressões, análise fatorial, modelos de equações estruturais etc. O exercício interpretativista e interacionista proposto ampliaria a visão de mundo em volta do pesquisador e auxiliaria a sua mais ampla compreensão. As tarefas interpretativistas poderiam ser propostas de forma semelhante às positivistas e oferecer mais opções aos pesquisadores para encontrar, observar, interpretar problemas de consumo e deles tratar. O Interacionismo Interpretativo pode ser utilizado como portal para novas dimensões de observação das relações de consumo.

\section{CONSIDERAÇÕES FINAIS}

O desafio de compreender melhor o comportamento do consumidor passa necessariamente pela ampliação das opções metodológicas disponíveis para a pesquisa acadêmica em marketing. Quando a perspectiva de entendimento do mundo do consumo é alterada, surgem problemas diferentes, que exigem visadas diferentes. Neste sentido, a pesquisa interpretativa pode representar importante ampliação do acervo de opções para o pesquisador da área. Tal proposta pode levar a uma expansão da compreensão do consumidor e resultar em novas teorias mais adequadas à própria realidade relacional brasileira.

A pesquisa interpretativa começa e termina com a biografia e o self do pesquisador (Denzin, 1989) e depende de suas habilidades de participação, entrevista e escuta. A preparação do pesquisador é necessária para o processo interpretativo; mas não é suficiente para a construção de uma pesquisa de caráter interpretativo, porquanto cada perspectiva metodológica possui características próprias. Mesmo apresentando proposta de ação assaz organizada, a prática do método do Interacionismo Interpretativo mostrou-se demasiadamente complexa. 
Este artigo tratou da discussão metodológica de uma tese de doutorado, que envolveu uma investigação mais diretamente focada no fenômeno emocional da vergonha no consumo e foi necessária uma orientação de caráter interpretativo, para que conseguíssemos agir dentro desta proposta. Outros pesquisadores poderiam ter pensado em problemas semelhantes de maneiras diferentes; mas, se perceberem isto, estarão aceitando o pressuposto interpretativo da tese. Cada interpretação é uma interpretação e não existe 'a' interpretação. De maneira bastante satisfatória, o Interacionismo Interpretativo (Denzin, 1989) ofereceu opções adequadas de investigação, organização e operação, dentro da proposta da tese. O método ofereceu também uma solução aplicada aos problemas de análise dos volumosos dados resultantes da abordagem qualitativa. A utilização do Interacionismo Interpretativo permitiu que permanecessemos totalmente focados no fenômeno em estudo, devido às características progressivas (step-like) da análise. Desta forma, nos sentimos mais à vontade para interpretar, de maneira bem-sucedida, aspectos do fenômeno emocional no consumo em nível mais profundo. Além disso, a abordagem adotada tornou possível o acesso às perspectivas dos participantes por meio de suas linguagens, atitudes e pensamentos. Como resultado, obtivemos uma interpretação mais rica das relações de consumo que envolvem a vergonha.

As etapas de coleta, bracketing e (re)construção transcorreram de maneira simultânea e tivemos de redesenhar a proposta original de Denzin (1989) durante a operação do método. A interação destas etapas, que parecia inicialmente um problema, demonstrou ser uma forma de enriquecer o processo interpretativo praticado na pesquisa. Enquanto revisitávamos os discursos coletados anteriormente, nós sofisticávamos o processo de coleta da entrevista posterior. Assim, a cada entrevista realizada, nos sentíamos mais capazes de nos aproximarmos do indivíduo e investigar suas construções a respeito de consumo e sentimentos de vergonha. A grande quantidade de dados e suas interpretações possibilitaram a (re)construção das formas de relação entre o sentimento de vergonha e os significados de consumo, a partir dos três casos apresentados.

O desenvolvimento da tese à qual esse trabalho se refere exigiu grande capacidade de controle do método e das ações de pesquisa; mas também serviu como forma de demonstrar que a utilização de métodos de orientação interpretativa pode ser muito produtiva para a pesquisa acadêmica de marketing. Durante este processo, percebemos que o pesquisador que opta por esta orientação poderá defrontar-se com a necessidade de adaptações do método à prática de pesquisa: desconstruções e reconstruções. A prática da pesquisa interpretativa demonstrou-se mais complexa e exigiu mais esforço de nossa capacidade criativa para a obtenção de resultados que fossem relevantes.

Voltamos ao quebra-cabeça de Pollock? Os métodos interpretativos, considerados moles, acabam sendo aqueles em que o pesquisador necessita investir muito mais tempo e dedicação. Muitas respostas não estão lá, expostas, esperando serem encontradas ou descobertas, como no mundo positivista natural. As respostas estão em locais diferentes, não necessariamente conectadas, mas desejando ser interpretadas. A pesquisa social é evento contraditório e confuso na sua prática. Dificilmente o pesquisador consegue seguir seu caminho de maneira linear e com protocolos plenamente definidos e estáveis.

Artigo recebido em 16.04.2009. Aprovado em 10.12.2009.

\section{NOTA}

\footnotetext{
${ }^{1}$ É importante realizar uma distinção entre a proposta de bracketing levada a cabo por Denzin (1989) da proposta original de Husserl. O bracketing, ou epoché, como define Husserl, é o momento em que o pesquisador coloca o fenômeno sob séria inspeção e consiste em explicitar o objeto tal como manifesto (noema) de uma determinada forma (noese) (Thiry-Cherques, H. R. (2004). Programa para aplicação às ciências da gestão de um método de caráter fenomenológico. In M. M. F. Vieira \& D. M. Zouain (Orgs.), Pesquisa qualitativa em administração (pp. 97-121). Rio de Janeiro: Editora FGV). Assim, a realidade é colocada entre parênteses, as crenças, preconceitos ou suposições sobre o objeto são suspensos. O movimento proposto por Denzin (1989) se alinha à proposta de Heidegger e considera que o bracketing não é possível sem a compreensão da situação mediada por um conhecimento externo prévio ou sem a sensibilidade às situações, compreendida pelo mundo vivido
} 
pelo pesquisador. Como parte necessária do ser para o mundo (Dasein), as coisas são percebidas de acordo com a forma com a qual elas são encontradas e usadas nas rotinas e tarefas diárias. A percepção e a apreensão se movem do conhecimento prévio para uma compreensão existencial.

\section{REFERÊNCIAS BIBLIOGRÁFICAS}

Ahuvia, A. C. (2005). Beyond the extended self: loved objects and consumers identity narratives. Journal of Consumer Research, 32(1), 171-184.

Andrade, S. M. O., \& Tanaka, O. Y. (2001). Interacionismo interpretativo: uma nova perspectiva teórica para as pesquisas qualitativas. Ensaios e Ciência, 5(3), 55-72.

Bagozzi, R. P., Gürhan-Canli, Z., \& Priester, J. R. (2002). The social psychology of consumer behavior. Buckingham: Open University Press.

Baudrillard, J. (1991). A sociedade de consumo. Lisboa: Edições 70.

Belk, R. W. (1985). Materialism: trait aspects of living in the material world. Journal of Consumer Research, 12(3), 265-280.

Berger, P. L., \& Luckman, T. (2004a). A construção social da realidade (24a ed.). Petrópolis: Ed. Vozes.

Berger, P. L., \& Luckmann, T. (2004b). Modernidade, pluralismo e crise de sentido: a orientação do homem moderno. Petrópolis: Ed. Vozes.

Blumer, H. (1998). Symbolic interactionism: perspective and method. Berkeley: University of California Press.

Brownlie, D., Saren, M., Wensley, R., \& Whittington, R. (Eds.). (1999). Rethinking marketing towards critical marketing accountings. London: Sage.

Casotti, L. M. (1998, setembro). Marketing moderno e consumidor pós-moderno? Anais do Encontro Nacional da Associação de Pós-Graduação e Pesquisa em Administração, Foz do Iguaçu, PR, Brasil, 22.

Costa, J. A., \& Belk, R. W. (1990). Nouveaux riches as quintessential americans: case studies of consumption in an extended family. Advances in Non Profit Marketing, 3(1), 83-140.

Denzin, N. K. (1983). A note on emotionality, self and interaction. The American Journal of Sociology, 89(2), 402-409.

Denzin, N. K. (1984). On understanding emotion. San Francisco: Jossey-Bass.

Denzin, N. K. (1989). Interpretive interactionism. London: Sage.

Douglas, M., \& Isherwood, B. (2004). O mundo dos bens: para uma antropologia do consumo. Rio de Janeiro: Editora da UFRJ.

Emmerling, L. (2003). Jackson Pollock: 1912 - 1956. Köln: Taschen. Recuperado em 14 junho, 2007, de http://www.globalgallery.com/enlarge/42776/

Farias, S. A. (2006, maio). Pesquisa flexível em marketing: o lado humanista de uma ciência socialmente construída e fixamente investigada. Anais do Encontro de Marketing da ANPAD, Rio de Janeiro, RJ, Brasil, 2. 
Garfinkel, H. (1967). Studies in ethnomethodology. Englewood Cliffs: Prentice-Hall.

Geertz, C. (1989). A interpretação das culturas. Rio de Janeiro: LTC.

Goulding, C. (1999). Consumer research, interpretive paradigms and methodological ambiguities. European Journal of Marketing, 33(9/10), 859-873.

Hochschild, A. (1979). Emotion work, feeling rules, and social structures. American Journal of Sociology, 85(3), 551-575.

Holbrook. M. B., \& Hirschman, E. C. (1982). The experiential aspects of consumption, feelings, and fun. Journal of Consumer Research, 9(2), 132 -140.

Holstein, J. A., \& Gubrium, J. F. (2005). Interpretive practice and social action. In N. K. Denzin \& Y. S. Lincoln (Eds.), Sage handbook of qualitative research (3th ed). Thousand Oaks: Sage.

Hudson, L. A., \& Ozanne, J. (1988). Alternative ways of seeking knowledge in consumer research. Journal of Consumer Research, 14(4), 508-521.

Kemper, T. D. (1981). Social constructivist and positivist approaches to the sociology of emotions. American Journal of Sociology, 87(2), 336-362.

Kemper, T. (2004). The differential impact of emotions on rational schemes of social organization: reading Weber and Coleman. In J. Turner (Ed.), Theory and research on human emotions. New York: Elsevier.

McCracken, G. (1988). The long interview. Newbury Park: Sage Publications.

Mohr, W. K. (1997). Interpretive interactionism: denzin's potential contribution to intervention and outcomes research. Qualitative Health Research, 7(2), 270-286.

Owens, E. (2006). Conversational space and participant shame in interviewing. Qualitative Inquiry, 12(6), 1160-1179.

Richins, M. L. (1997). Measuring emotions in the consumption experience. Journal of Consumer Research, 24(2), 127-146.

Scheff, T. J. (1990). Microsociology: discourse, emotion and social structure. Chicago: The University of Chicago Press.

Shott, S. (1979). Emotion and social life: a symbolic interactionist analysis. The American Journal of Sociology, 84(6), 1317-1334.

Vieira, F. G. D. (2000, setembro). Panorama acadêmico-científico e temáticas de estudos de marketing no Brasil. Anais do Encontro Nacional da Associação de Pós-Graduação e Pesquisa em Administração, Florianópolis, SC, Brasil, 24. 